Tropical Journal of Pharmaceutical Research February 2011; 10 (1): 97-103

(C) Pharmacotherapy Group, Faculty of Pharmacy, University of Benin,

Benin City, 300001 Nigeria.

All rights reserved.

Research Article

Available online at http://www.tjpr.org

\title{
Simultaneous Analysis of Bioactive Markers from Orthosiphon Stamineus Benth Leaves Extracts by Reverse Phase High Performance Liquid Chromatography
}

\section{Mohammad Jamshed Ahmad Siddiqui* and Zhari Ismail}

Pharmaceutical Chemistry, School of Pharmaceutical Sciences, Universiti Sains Malaysia, 11800 Minden, Penang, Malaysia

\begin{abstract}
Purpose: To develop a reverse phase high performance liquid chromatography (RP-HPLC) method for the analysis of the crude extracts of Orthosiphon stamineus.

Methods: A simple and facile analytical method was developed using RP. HPLC with UV detection for the identification and quantitation of bioactive markers present in $O$. stamineus extracts. Four different bioactive markers were used for the analysis, namely, rosmarinic acid; orthosiphol-A, 3'-hydroxy-5, 6, 7, 4'-tetramethoxyflavone (TMF) and 5, 6, 7, 3', 4'-pentamethoxyflavone (sinensetin), using an isocratic mobile phase methanol: tetrahydrofuran: water $\left(0.1 \% \mathrm{H}_{3} \mathrm{PO}_{4}\right)$ (55:5:40) on Nucleosil C-18 column (250 $\mathrm{mm} \times 4.6 \mathrm{~mm}$ i.d., $5 \mu \mathrm{m}$ particle size) at a flow rate of $0.7 \mathrm{ml} / \mathrm{min}$ and detection at $330 \mathrm{~nm}$ with $30 \mathrm{~min}$ separation time.

Results: The bioactive marker orthosiphol $A$ was identified and isolated from the water extract of $O$. stamineus leaves. The standard calibration curves for the marker were linear in the range $0.01-500$ $\mu \mathrm{g} / \mathrm{ml}$ with a regression coefficient $\left(r^{2}\right)>0.9996$. The recoveries of the four markers were in the range 83.2 to $106.4 \%$ at relative standard deviation (RSD) values $<5 \%$. The limit of detection (LOD) and of quantification (LOQ) were 2 and $20 \mathrm{ng} / \mathrm{ml}$, respectively.

Conclusion: The developed method is simple, sensitive and specific for simultaneous determination of the indicated marker compounds either qualitatively or quantitatively, and may be used as a fingerprint profile for the standardization of extractives or herbal medicines from $\mathrm{O}$. stamineus.
\end{abstract}

Keywords: Orthosiphon stamineus, Orthosiphol A, Rosmarinic acid, Sinensetin, Isocratic, Quantification, HPLC 


\section{INTRODUCTION}

Orthosiphon stamineus (OS), Benth, (Lamiaceae) is one of the most useful traditional medicinal herbs cultivated in South East Asia, particularly Malaysia and Indonesia. Being popularly known as Java tea, this herb is widely used in traditional medicine to treat many ailments due to its activities such as diuretic, urolithiatic, antiinflammatory, anticholestatic, analeptic, antirheumatic as well as antidiabetic [1,2]. The leaves of $O$. stamineus have been used as a diuretic in the form of infusions in a wide variety of kidney and bladder pathologies, especially kidney stones, pain in the bladder with frequent urination, as well as accumulation of uric acid crystals in joints owing to elevated blood uric acid levels [3-5].

Technological strides in chromatographic and spectroscopic methods have brought tremendous influence on the isolation and structural elucidation of a variety of medicinal plants constituents. The recent surge of interest in $O$. stamineus has led to the isolation and identification of several classes of bioactive compounds such as flavanoids, diterpenes, triterpenes, saponins, sterols organic acids, caffeic acids derivatives and chromenes [69]. Hussain and associates isolated betulinic acid, 16- $\beta$-hudroxybetulinic acid and rosmarinic acid from this plant in Malaysia $[10,11]$. Numerous studies have also been performed to investigate the biological effects of $O$. stamineus as antioxidant, diuretic, antifungal as well as in alleviating hyperglycaemia and improving lipid profile in diabetic rats $[3,9,12]$. Earlier studies suggest that the flavones, sinensetin and 3'-hydroxy-5, 6, 4'-tetramethoxyflavone isolated from $O$. stamineus exhibited diuretic activity in rats which may be partially due to its lipophilic flavone content [12]. Recently, antiangiogenic activity has been attributed to the plant $[13,17]$.

The aim of this study is to develop a simple and sensitive method for the simultaneous quantification of bioactive markers which can be used for the quality control of herbal products derived from $O$. stamineus plant.

\section{EXPERIMENTAL}

\section{Plant material}

Orthosiphon stamineus plant was cultivated and propagated under controlled conditions in a joint venture with USM-UNIMAP at Titi Tinggi, Perlis, Malaysia. A voucher specimen (no. 11009) was deposited at the herbarium of the School of Biology, Universiti Sains Malaysia. The leaves were collected in the month of July and August 2009 and pulverized into a fine powder using a milling machine (Retsch GmbH, Germany).

\section{Chemical and reagents}

HPLC grade methanol, acetonitrile, tetrahydrofuran and ortho-phosphoric acid were purchased from Merck, Germany. Reference standards - sinensetin, 3'-hydroxy5, 6, 7, 4'-tetramethoxyflavone (TMF) and rosmarinic acid - were purchased from Indo Fine Chemical Company, Hillsborough, USA. Deionised water for HPLC was prepared using ultra pure water purifier system (Elgastat, Bucks, UK). Chemicals and solvents (analytical grade) for isolation of orthosiphol A were purchased from Merck Germany, while Silica gel $60 \mathrm{~F}_{254}$ preparative TLC and analytical TLC were purchased from E Merck, Germany.

\section{Preparation of extract}

The powdered crude drug extracted with water or methanol or with the following methanol: water mixtures: 75:25, 50:50, 25:75, using a Soxhlet extractor (for $12 \mathrm{~h}$ ) in the case of methanol and methanol:water extraction. For water extraction, hot maceration at $50{ }^{\circ} \mathrm{C}$ for $6 \mathrm{~h}$ was employed and then repeated thrice. In each case, the extract was bulked and concentrated in a rotary evaporator under vacuum, and then freeze-dried. The lyophilized extracts were kept in a freezer until used. 


\section{Isolation of orthosiphol A}

The dried extract was re-dissolved in water:acetone (90:10) mixture and extracted with hexane, separating the upper layer of hexane with the aid of a separating funnel. The mother liquor was again extracted with dichloromethane and the lower layer of dichloromethane-rich extract was separated. Mother liquor again was extracted with nbutanol and the butanol-rich upper layer containing the extract was separated. Each of the extract type was concentrated and dried in a rotavapor under high vacuum.

The dichloromethane-rich extract was adsorbed on silica gel and column chromatography was performed using a glass column $(30 \times 2.5 \mathrm{~cm})$ packed with silica gel (70 - 230 mesh), eluting it with hexane by increasing its polarity with ethyl acetate. Several fractions (fractions 2 and 4) were collected and monitored on TLC. Fraction 2 was again chromatographed with $2.5 \%$ methanol in chloroform over silica gel (70 230 mesh). Further purification was carried out with preparative thin layer chromatography to yield a pure compound. Purity (95 $\%)$ of compounds was confirmed by HPLC (Agilent Technologies). The identification and characterization of isolated compounds were performed by comparing ultraviolet (UV), Fourier transform infrared (FTIR), mass spectrometry (MS) and nuclear magnetic resonance (NMR) spectra as described previously [8].

\section{Sample preparation for HPLC analysis}

Samples of extract (100 mg each) were dissolved in $25 \mathrm{ml}$ mixture of methanol: water (1:1), and sonicated for $10-15 \mathrm{~min}$. The contents were transferred to a $25 \mathrm{ml}$ volumetric flask, made up to the $25 \mathrm{ml}$ mark and filtered through a $0.45 \mu \mathrm{m}$ filter (Whatman). In the same way, the reference compounds (about $5 \mathrm{mg}$ each) were dissolved in $5 \mathrm{ml}$ of methanol and then filtered through a $0.45 \mu \mathrm{m}$ filter. The stock solutions were used for further dilutions.
Samples were kept in freezer at $-20{ }^{\circ} \mathrm{C}$ prior to analysis.

\section{Instrumentation and chromatographic conditions}

High performance liquid chromatography (HPLC, Agilent Technologies Series 1100 system) used was equipped with a degasser, an auto sampler, a column heater, quaternary pump and UV detector. The column (Nucleosil C18, $250 \mathrm{~mm} \times 4.6 \mathrm{~mm}, 5 \mu \mathrm{m}$ ) was maintained at $25{ }^{\circ} \mathrm{C}$ and The injected sample $(20 \mu \mathrm{l})$ was eluted with an isocratic mobile phase comprising of methanol: tetrahydrofuran:water $\left(0.1 \% \mathrm{H}_{3} \mathrm{PO}_{4}\right)$ mixture in the volume ratio $55: 5: 40$. Flow rate was 0.7 $\mathrm{ml} / \mathrm{min}$, separation time $30 \mathrm{~min}$, and detection at $330 \mathrm{~nm}$. Data acquisition was performed with the aid of ChemStation A.08.03. Standard calibration curves were established by plotting the peak area against concentration.

The reference compounds used were: rosmarinic acid, orthosiphol A, 3'hydroxy-5, 6, 7, 4'-tetramethoxyflavone and 5, 6, 7, 4', 5'pentamethoxyflavone or sinensetin (see Fig $1)$.

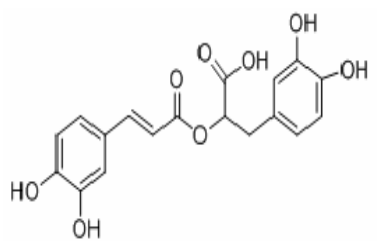

Rosmarinic acid(1)

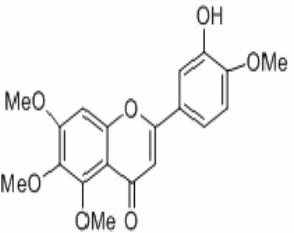

3'-hydroxy-5,6,7,4'-tetramethoxyflavone(3)

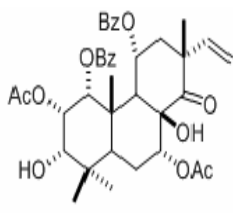

Orthosiphol A(2)

Fig 1: Chemical structures of reference compounds 
Determination of limits of detection (LOD), limits of quantification (LOQ), and linearity

The linearity of the calibration curves was evaluated by linear regression analysis and correlation coefficient $\left(R^{2}\right)$. Limit of detection (LOD) was established at a signal-to-noise ratio $(\mathrm{S} / \mathrm{N})$ of 3 while limits of quantification (LOQ) were established at a signal-to-noise ratio $(\mathrm{S} / \mathrm{N})$ of 10 . $L O D$ and $L O Q$ were experimentally verified by six injections of each standard. LOD and LOQ) were evaluated by measuring the magnitude of analytical background after injecting the blank sample.

Table 1: Linear correlation between peak area and concentration

\begin{tabular}{|c|c|c|c|c|c|}
\hline $\begin{array}{l}\frac{0}{\pi} \\
\frac{\pi}{0} \\
\frac{5}{\pi} \\
\text { के }\end{array}$ & 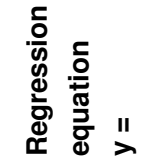 & ఇָ & 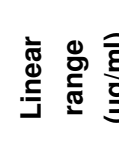 & 옳 & ○ \\
\hline $\mathrm{RA}(1)$ & $\begin{array}{l}36.88 x- \\
18.54\end{array}$ & 0.999 & $\begin{array}{l}0.01- \\
500\end{array}$ & 2.0 & 20 \\
\hline $\operatorname{Or} \mathrm{A}(2)$ & $\begin{array}{l}23.076 x \\
-12.36\end{array}$ & 0.999 & $\begin{array}{l}0.01- \\
500\end{array}$ & 2.0 & 20 \\
\hline TMF(3) & $\begin{array}{l}49.878 x \\
-11.69\end{array}$ & 0.999 & $\begin{array}{l}0.01- \\
500\end{array}$ & 2.0 & 20 \\
\hline
\end{tabular}

\section{Method validation}

The precision and accuracy of the method was performed by within day and between day run validations. Each standard curve was separately constructed on each day of analysis. The within day precision and accuracy were determined for each standard on three concentration with five replicates on a single day. The resulting retention time and peak area were used to calculate standard deviation and relative standard deviation (\% RSD). The accuracy of the method was verified by recovery studies by spiking the standards at three different concentration levels. Accuracy was calculated from plot of the value of detection versus added amounts.

\section{Statistical analysis}

Samples were analysed in triplicate for recovery and the mean taken. For LOD and $L O Q$, intra-day and inter-day accuracy the mean $(n=5)$ was taken. The mean data were compared by one-way ANOVA using SPSS, version 13.0

\section{RESULTS}

\section{Characterization and structure elucidation of isolated compound (2)}

Isolated compound (2) was identified as orthosiphol A and was used as reference compound for determination of crude extracts obtained from $O$. stamineus leaves.

Orthosiphol A white amorphous solid (10 $\mathrm{mg}$ ), Rf 0.3 [Silica gel, solvent Toluene: Acetone (85:15)]. LC-MS gave $\mathrm{m} / \mathrm{z} 677$ $[\mathrm{M}+\mathrm{H}]$; UV $(\mathrm{MeOH}) \lambda \max : 230,280, \mathrm{~nm}$; FTIR (KBr): 3445, 2951, 1741, 1281, 1245, $780 \mathrm{~cm}^{-1}$. ${ }^{1} \mathrm{H}$ NMR $\left(\mathrm{CDCl}_{3}\right) \delta: 1.01-1.15(9 \mathrm{H}$, s, H17,H18\& H19), $1.43(3 \mathrm{H}, \mathrm{s}, \mathrm{H} 20), 1.90$ $(3 \mathrm{H}, \mathrm{s}, 2-\mathrm{Ac}), 2.21$ (3H, s, 7-Ac), 5.31 $(1 \mathrm{H}$, brd, $\mathrm{J}=2.6 \mathrm{~Hz}, \mathrm{H} 1), 5.42(1 \mathrm{H}, \mathrm{brt}, \mathrm{J}=3.2 \mathrm{~Hz}$, $\mathrm{H} 2), 3.55(1 \mathrm{H}, \mathrm{m}, \mathrm{H} 3), 2.45(1 \mathrm{H}, \mathrm{dd}, \mathrm{J}=10$ and $4.5 \mathrm{~Hz}, \mathrm{H} 5), 2.1-2.22(1 \mathrm{H}, \mathrm{m}, \mathrm{H} 6), 5.45$ $(1 \mathrm{H}$, brt, J=3.2Hz, H7), $3.12(1 \mathrm{H}, \quad$ brd, $\mathrm{J}=5.7 \mathrm{~Hz}, \mathrm{H} 9), 5.82(1 \mathrm{H}, \mathrm{m}, \mathrm{H} 11), 1.99(1 \mathrm{H}$, dd, H12), $2.54(1 \mathrm{H}, \mathrm{dd}, \mathrm{H} 12), 5.63(1 \mathrm{H}, \mathrm{dd}$, $\mathrm{H} 15), 4.82(1 \mathrm{H}, \mathrm{d}, \mathrm{H} 16), 4.86(1 \mathrm{H}, \mathrm{d}, \mathrm{H} 16)$, $7.21-7.78(10 \mathrm{H}, \mathrm{t}, 1 \& 11-\mathrm{Bz}), 2.20(1 \mathrm{H}, \mathrm{d}, 3-$ $\mathrm{OH}), 2.85\left(1 \mathrm{H}\right.$, brs, 8-OH). ${ }^{13} \mathrm{C}$ NMR (CDCl3) ঠ: 75.1 (C1), 65.8 (C2), 77.3 (C3), 38.9 (C4), 34.6 (C5), 21.2 (C6), 71.2 (C7), 76.9 (C8), 43.2 (C9), 44.1 (C10), 69.3 (C11), 39.0 (C12), 46.3 (C13), 209.1 (C14), 144.2 (C15), 112 (C16), 26.9 (C17), 22.9 (C18), 29.9 (C19), 15.9 (C20), 21.1 (2-Ac), 173 (2-Ac), 21.1 (7-Ac), 167.1 (7-Ac), 165 (1-Bz), 167 (11-Bz), 136 (1-Bz), 135 (11-Bz), 127.2 (1$\mathrm{Bz}), 128.3$ (11-Bz); LC-MS gave $\mathrm{m} / \mathrm{z} 677$ $[\mathrm{M}+\mathrm{H}]$. Spectral data were consistent with that reported for orthosiphol A [8]. 
Table 2: Within day and between day data for standards

\begin{tabular}{|c|c|c|c|c|c|}
\hline \multirow{2}{*}{$\begin{array}{l}\text { Standard } \\
\text { (Rt } \pm S D)\end{array}$} & \multirow{2}{*}{$\begin{array}{l}\text { Concentration } \\
(\mu \mathrm{g} / \mathrm{ml})\end{array}$} & \multicolumn{2}{|c|}{ Within day $(n=5)$} & \multicolumn{2}{|c|}{ Between day $(n=25)$} \\
\hline & & $\begin{array}{l}\text { RSD (\%) } \\
\text { (Time) }\end{array}$ & $\begin{array}{l}\text { RSD (\%) } \\
\text { (Area) }\end{array}$ & $\begin{array}{l}\text { RSD (\%) } \\
\text { (Time) }\end{array}$ & $\begin{array}{l}\text { RSD (\%) } \\
\text { (Area) }\end{array}$ \\
\hline \multirow{3}{*}{$\mathrm{RA}(5.7 \pm 0.0)$} & 100 & 0.01 & 0.54 & 0.08 & 0.64 \\
\hline & 60 & 0.09 & 0.55 & 0.17 & 2.6 \\
\hline & 20 & 0.6 & 0.42 & 0.17 & 0.66 \\
\hline \multirow[t]{3}{*}{ Ortho $(7.0 \pm 0.0)$} & 100 & 0.17 & 1.88 & 0.15 & 0.13 \\
\hline & 50 & 0.07 & 0.73 & 0.15 & 0.71 \\
\hline & 20 & 0.07 & 0.21 & 0.38 & 0.24 \\
\hline \multirow[t]{3}{*}{ TMF $(10.8 \pm 0.0)$} & 100 & 0.05 & 0.63 & 0.26 & 0.26 \\
\hline & 60 & 0.15 & 0.44 & 0.1 & 0.19 \\
\hline & 10 & 0.17 & 0.45 & 0.09 & 0.06 \\
\hline \multirow[t]{3}{*}{ SEN (13.6 \pm 0.1$)$} & 100 & 0.08 & 0.64 & 0.21 & 0.12 \\
\hline & 60 & 0.75 & 0.07 & 0.2 & 0.19 \\
\hline & 20 & 0.16 & 1.2 & 0.24 & 0.28 \\
\hline
\end{tabular}

$R A=$ rosmarinic acid; Ortho $=$ orthosiphol $A ; T M F=3$ 'hydroxy-5, 6, 7, 4'-tetramethoxyflavone; SEN = sinensetin

Table 3: Within day recovery of marker compounds

\begin{tabular}{lcccc}
\hline Standard & $\begin{array}{c}\text { Concentration } \\
(\boldsymbol{\mu} \mathbf{g} / \mathbf{m l})\end{array}$ & $\begin{array}{c}\text { Amount } \\
(\boldsymbol{\mu} \mathbf{g} / \mathbf{m l})\end{array}$ & $\begin{array}{c}\text { Recovery } \\
\%\end{array}$ & $\begin{array}{c}\text { RSD } \\
\%\end{array}$ \\
\hline RA & 100 & 98.93 & 98.93 & 0.55 \\
& 60 & 58.92 & 98.20 & 0.56 \\
Ortho A & 20 & 18.79 & 93.95 & 0.94 \\
& 100 & 99.30 & 99.30 & 0.19 \\
TMF & 50 & 48.82 & 97.64 & 0.73 \\
& 20 & 18.79 & 93.95 & 0.21 \\
SEN & 100 & 99.26 & 99.26 & 0.69 \\
& 60 & 59.85 & 99.75 & 0.10 \\
& 10 & 9.53 & 95.30 & 0.42 \\
& 100 & 99.94 & 99.94 & 0.61 \\
& 60 & 59.67 & 99.45 & 0.07 \\
& 20 & 19.59 & 97.95 & 1.13 \\
\hline
\end{tabular}

$R A=$ rosmarinic acid; Ortho $=$ orthosiphol $A ; T M F=3^{\prime}$ hydroxy $-5,6,7,4^{\prime}$-tetramethoxyflavone; $S E N=$ sinensetin

Table 4: Content of markers (\% dry weight) of $O$. stamineus leaf extracts

\begin{tabular}{llcccc}
\hline $\begin{array}{l}\text { Extract } \\
\text { code }\end{array}$ & Extraction solvent & $\begin{array}{c}\text { Rosmarinic } \\
\text { acid (1) }\end{array}$ & $\begin{array}{c}\text { Orthosiphol } \\
\mathbf{A ( 2 )}\end{array}$ & TMF (3) & $\begin{array}{c}\text { Sinensetin } \\
\mathbf{( 4 )}\end{array}$ \\
\hline $\mathrm{A}$ & Meth & $1.58 \pm 0.10$ & $0.18 \pm 0.00$ & $0.18 \pm 0.01$ & $0.58 \pm 0.01$ \\
$\mathrm{~B}$ & Meth:Water (75:25) & $1.12 \pm 0.00$ & $0.12 \pm 0.02$ & $0.07 \pm 0.20$ & $0.19 \pm 0.11$ \\
$\mathrm{C}^{*}$ & Meth:Water (50:50) & $2.54 \pm 0.01$ & $0.24 \pm 0.01$ & $0.11 \pm 0.01$ & $0.21 \pm 0.01$ \\
$\mathrm{D}^{* *}$ & Meth:Water (50:50) & $2.12 \pm 0.01$ & $0.20 \pm 0.10$ & $0.09 \pm 0.00$ & $0.22 \pm 0.00$ \\
$\mathrm{E}$ & Meth:Water (25:75) & $0.35 \pm 0.01$ & $0.91 \pm 0.01$ & $0.05 \pm 0.00$ & $0.41 \pm 0.00$ \\
$\mathrm{~F}$ & Water & $1.18 \pm 0.00$ & $0.03 \pm 0.00$ & $0 \pm 0.00$ & $0.02 \pm 0.01$ \\
\hline
\end{tabular}

${ }^{*}$ Freeze-dried; ${ }^{* *}$ Spray-dried; Meth $=$ methanol

\section{Limits of detection (LOD) and quantitation (LOQ)}

Table 1 indicates the calibration, LOD and LOQ data for the standarda. The curve was linear over the entire concentration range investigated with correlation coefficient ranging from 0.9996 to 0.9999 and standard deviation less then $\pm 5 \%$. LOD and LOQ for the standards were 2 and $20 \mathrm{ng} / \mathrm{ml}$, respectively, at a signal to noise ratio of 1:10. 


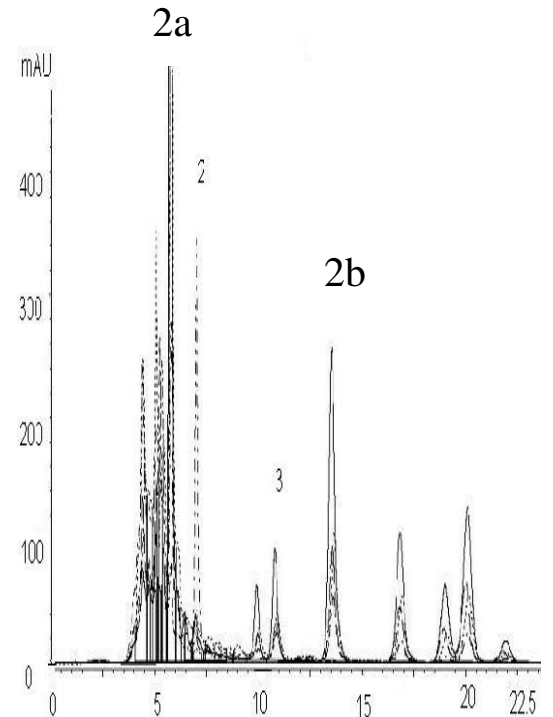

Fig 2: A typical chromatograph of standard markers (2a) and typical overlaid HPLC chromatographs of all the crude extract samples (2b)

\section{Retention time, recovery and precision}

As Table 3 shows, the mean retention time for the markers - rosmarinic acid, orthosiphol A, TMF and sinensetin $=$ was $5.6 \pm 0.02,6.5$ $\pm 0.01,9.9 \pm 0.04$, and $12.2 \pm 0.09$, respectively, while RSD was in the range of 0.06 to 2.4 which is less than $5 \%$. Recovery for the markers was in the range 93.95 to 99.95. The results indicate that the method is reliable and reproducible for the determination of the isolates of $O$. stamineus leaf extract.

\section{Marker contents of $\boldsymbol{O}$. stamineus extracts}

As shown in Table 4 indicates, all the analysed samples showed a wide range in marker contents. Methanol extract contained the highest amounts of sinensetin but also contained other markers. Methanol:water (1:1) extract was rich in rosmarinic acid while methanol:water (25:75) extract was rich in orthosiphol A. These results are in agreement with previous findings [12].

\section{DISCUSSION}

Some methods have previously been used for the analysis of $O$. stamineus leaf extract [12-15]. The focus of the present work is on anticancer markers for the purpose of preparing standardized extracts for the analysis of anticancer and antiangiogenic activity profiling $[13,17]$.

Sahib and associates highlighted that role of antioxidants in the antiangiogenic activity of the methanol extract of $O$. stamineus [13]. The high contents of rosmarinic acid and sinensetin $[12,14]$ in the methanol and methanol:water (1:1) extracts may be the reason for their antiangiogenic activity is higher for the methanol extract [13] than for the freeze-dried and spray-dried methanol: water (1:1) extracts [17]. The overlaid chromatographs (see Figure $2 b$ ) suggest that the developed method is best suited for flavonoids markers because the other prominent peaks at Rt of $18-23$ min may be other lipophilic flavonoids or may contain methyl ripariochromene compounds [15].

\section{CONCLUSION}

The proposed method is simple, sensitive and specific for simultaneous determination of marker compounds, either qualitatively or quantitatively. This method can be used as a fingerprint profile for the standardization of both extractives and herbal medicines derived from the $O$. stamineus.

\section{ACKNOWLEDGEMENT}

The authors would like to thank Universiti Sains Malaysia for providing fellowship and also the Ministry of Science and Technology, Malaysia for extending a grant for the work.

\section{REFERENCES}

1. Tiktinskii OL, Bablumian IA. Therapeutic action of Java tea and field horsetail in uric acid

Trop J Pharm Res, February 2011;10 (1):102 
diathesis. Urol Nefrol (Mosk). Russian; 1983; $p$ 47

2. Wiart C. Orthosiphon stamineus Benth. In: Medicinal Plants of Southeast Asia. Wong FK, Ed. Prentice Hall, Kuala Lumpur, 2002; $p 265$

3. Dat DD, Ham NN, Khac DH, Lam N, Son TPT, Dau $N V$, Grabe $M$ Johansson $R$ Lindgren G and Stjernstrom NE. Studies on the individual and combined diuretic effects of four Vietnamese traditional herbal remedies (Zea mays, Imperata cylindrical, Plantago major and Orthosiphon stamineus). J Ethnopharmacol 1992; 36: 225-231.

4. Tezuka $Y$, Stampoulis $P$, Banskota $A H$, Awale $S$, Tran KQ, Saiki S, Kadota S. Constituents of the Vietnamese Medicinal Plant Orthosiphon stamineus. Chem Pharm Bull 2000; 48: 1711-1719.

5. Awale S, Tezuka Y, Banskota AH, Kouda K, Tun KM, Kadota S. Five novel highly oxygenated diterpenes of Orthosiphon stamineus from Myanmar. J Nat Prod 2001; 64: 592-596.

6. Malterud KE, Hanche-Olsen IM, Smith-Kiekkand I. Flavonoids from Orthosiphon spicatus. Planta Med 1989; 55: 569-570.

7. Sumaryono $W$, Proksch $P$, Wravy $V$, Witte $L$, Hartmann T. Qualitative and Quantitative Analysis of the Phenolic Constituents from Orthosiphon stamineus. Planta Med 1991; 57: $176-180$.

8. Masuda T, Masuda K, Nakatani N. Orthosiphol A - a highly oxygenated diterpene from the leaves of Orthosiphon stamineus. Tetrahedron Lett 1992; 33: 945- 946.

9. Olah NK, Radu L, Mogoan C, Hanganu D, Gocan S. Phytochemical and pharmacological studies on Orthosiphon stamineus Benth.(Lamiaceae) hydro alcoholic extracts. J Pharm Biomed Anal 2003; 33: 117-123.

10. Hossain M A, Ismail Z. Hydroxy betulinic acid from the leaves of Orthosiphon stamineus . ACGC Chem.Res.Commun. 2003; 16: 69-73.
11. Hossain MA, Salehuddin SM, Ismail Z. Rosmarinic acid and methyl rosmarinate from Orthosiphon stamineus Benth. J Bangladesh Acad Sci 2006; 30: 167-172.

12. Akowuah GA, Ismail Z, Norhayati I, Sadikun A, Khamsah SM. Sinensetin, eupatorin, 3'hydroxy-5, 6, 7, 4'-tetramethoxyflavone and rosmarinic acid contents and antioxidative effect of Orthosiphon stamineus from Malaysia. Food Chem 2004; 87: 559-566.

13. Sahib HB, Aisha AF, Yam MF, Asmawi MZ, Ismail $Z$, Salhimi S M, Othman NH, Abdul Majid A $M S$. Anti-angiogenic and antioxidant properties of Orthosiphon stamineus Benth. Methanolic leaves extract. Int J. Pharmacol 2009; 5(2): 162-167.

14. Akowuah GA, Ismail Z, Norhayati I, Sadikun A. The effects of different extraction solvents of varying polarities on polyphenols of orthosiphon stamineus and evaluation of the free radical-scavenging activity. Food Chem 2005; 93: 311-317.

15. Pietta PG, Mauri PL, Gardana C, Bruno A. Highperformance liquid chromatography with diodearray ultraviolet detection of methoxylated flavones in Orthosiphon leaves. J Chromatogr A 1991; 547: 439- 442.

16. Mouly P, Gaydou EM, Auffray A. Simultaneous separation of flavanone glycosides and polymethoxylated flavones in citrus juices using liquid chromatography. $J$ Chromatogr $A$ 1998; 800: 171-179.

17. Siddiqui M J, Hafizoh S N, Ismail Z, Sahib HB, Helal MHS, Majid AMS. Analysis of Total proteins, polysaccharides and glycosaponins contents of Orthosiphon stamineus Benth. In spray and Freeze dried methanol: water (1:1) extract and its contribution to cytotoxic and angiogenic activities. Phcog Res. 2009; 1(5): 320-326. 